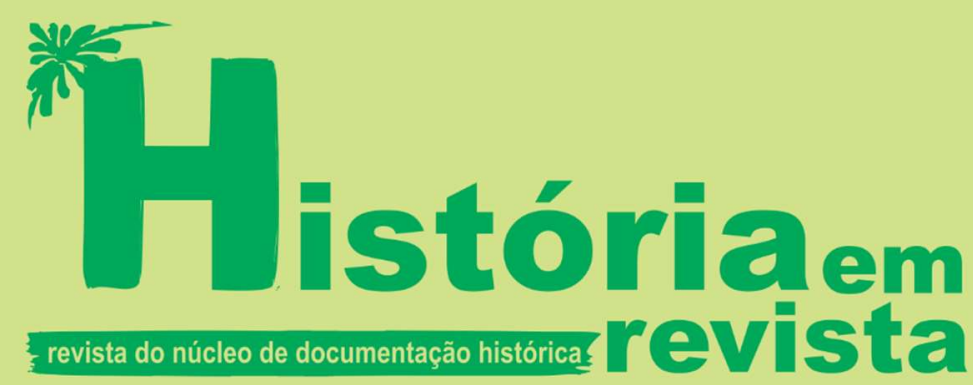

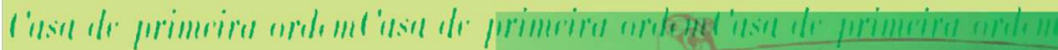

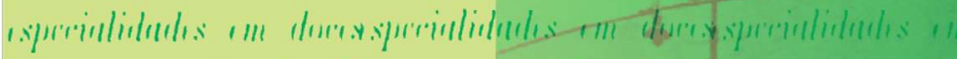

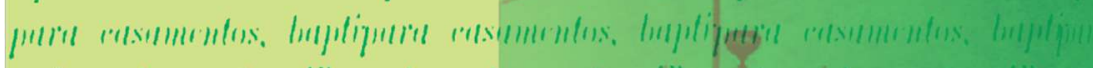

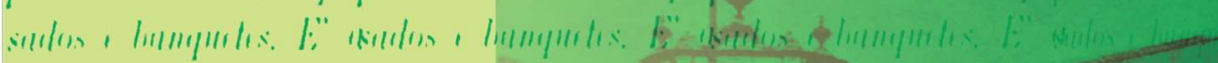

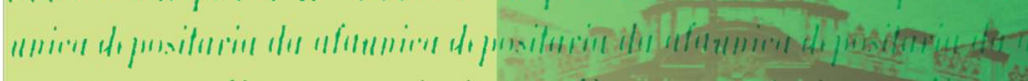

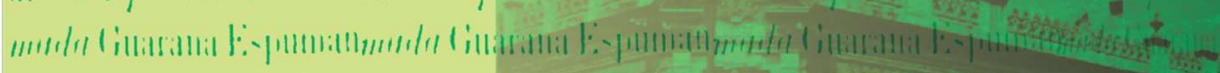

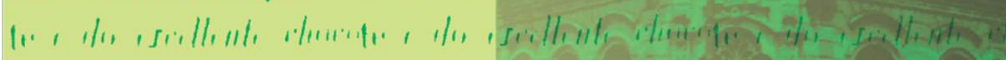

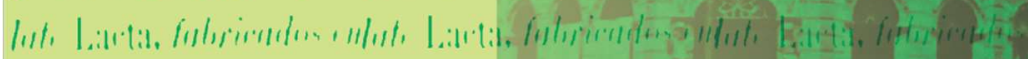

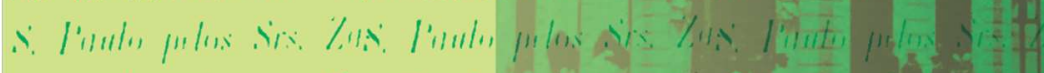

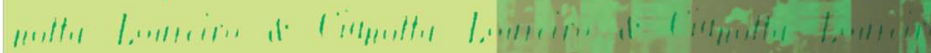

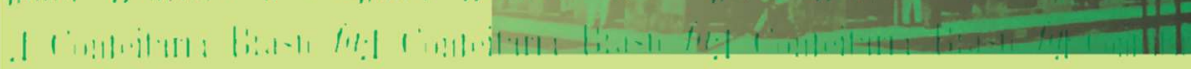




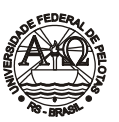

Obra publicada pela Universidade Federal de Pelotas Reitor: Pedro Rodrigues Curi Hallal Vice-Reitor: Luis Isaías Centeno do Amaral

Chefe de Gabinete: Aline Elias Lamas

Pró-Reitor de Graduação: Maria de Fátima Cóssio

Pró-Reitor de Pesquisa e Pós-Graduação: Flávio Fernando Demarco

Pró-Reitor de Extensão e Cultura: Francisca Ferreira Michelon

Pró-Reitor de Planejamento e Desenvolvimento: Otávio Martins Peres

Pró-Reitor Administrativo: Ricardo Hartlebem Peter

Pró-Reitor de Infra-estrutura: Julio Carlos Balzano de Mattos

Pró-Reitor de Assuntos Estudantis: Mário Renato de Azevedo Jr.

Pró-Reitor de Gestão Pessoas: Sérgio Batista Christino

\section{CONSELHO EDITORLAL}

Representante das Ciências Agronômicas: Guilherme Albuquerque de Oliveira Cavalcanti (Titular), Cesar Valmor Rombaldi (suplente) e Fabrício de Vargas Arigony Braga (suplente) | Representantes da Área das Ciências Exatas e da Terra: Adelir José Strieder (titular) e Juliana Pertille da Silva (suplente) | Representante da Área das Ciências Biológicas: Raquel Ludke (suplente) | Representante da Área das Engenharias e Computação: Darci Alberto Gatto | Representantes da Área das Ciências da Saúde: Claiton Leoneti Lencina (titular) e Giovanni Felipe Ernst Frizzo (suplente) | Representante da Área das Ciências Sociais Aplicadas: Célia Helena Castro Gonsales | Representante da Área das Ciências Humanas: Charles Pereira Pennaforte e Guilherme Camargo Massaú (suplente) | Representantes da Área das Linguagens e Artes: Josias Pereira da Silva (titular) e Maristani Polidori Zamperetti (suplente)

\section{INSTITUTO DE CIÊNCLAS HUMANAS}

Diretor: Prof. Dr. Sidney Gonçalves Vieira

Vice-Diretor: Prof. Dr. Sebastião Peres

\section{NÚCLEO DE DOCUMENTACÃO HISTÓRICA}

Coordenadora:

Prof ${ }^{a}$ Dra. Lorena Almeida Gill

Membros do NDH:

Prof ${ }^{a}$ Dra. Beatriz Ana Loner

Prof ${ }^{a}$ Dra. Lorena Almeida Gill

Prof. Dr. Paulo Ricardo Pezat

Prof. Dr. Aristeu Elisandro Machado Lopes

Técnico Administrativo:

Paulo Luiz Crizel Koschier

HISTÓRIA EM REVISTA - Publicação do Núcleo de Documentação Histórica

Comissão Editorial:

Prof. Dr. Aristeu Elisandro Machado Lopes

Prof ${ }^{a}$ Dra. Beatriz Ana Loner

Prof ${ }^{a}$ Dra. Lorena Almeida Gill

Prof. Dr. Paulo Ricardo Pezat

Conselho Editorial:

Prof ${ }^{a}$ Dra. Helga I. Landgraf Piccolo (UFRGS)

Prof. Dr. René Gertz (UFRGS) (PUCRS)

Prof. Ms. Mario Osorio Magalhães (UFPel)

Prof. Dr. Temístocles A. C. Cezar (UFRGS)

Profa. Dra. Beatriz Teixeira Weber (UFSM)

Prof ${ }^{a}$. Dra. Maria Cecília V. e Cruz (UFBA)

Prof. Dr. Marcelo Badaró Mattos (UFF)

Profa. Dra. Joan Bak (Univ. Richmond - USA)

Prof. PhD Pablo Alejandro Pozzi (Universidad de Buenos Aires).

Prof. Tommaso Detti (Università Degli Studi di Siena)

Editor: Prof. Dr. Aristeu Elisandro Machado Lopes

Editoração e Capa: Paulo Luiz Crizel Koschier

Editora e Gráfica Universitária

R Lobo da Costa, 447 - Pelotas, RS - CEP 96010-150 |

Fone/fax: (53) 32278411

e-mail: editora@ufpel.edu.br

\section{Impresso no Brasil}

Edicão: 2017

ISSN - 1516-2095

Dados de catalogação na fonte: Aydê Andrade de Oliveira - CRB - 10/864

História em revista / publicação do Núcleo de Documentação Histórica. Instituto de Ciências Humanas. Universidade Federal de Pelotas. v.23, (dez. 2017). - Pelotas: Editora da UFPel, 2017.

$1 \mathrm{v}$.

Anual

ISSN 1516-2095

1. História - Periódicos. I. Núcleo de Documentação Histórica. Instituto de Ciências Humanas. Universidade Federal de Pelotas. CDD 930.005

\section{Indexada pela base de dados Worldcat Online Computer Library Center}

\section{PEDE-SE PERMUTA} WE ASK FOR EXCHANGE

UFPel/NDH/Instituto de Ciências Humanas

Rua Cel. Alberto Rosa, 154

Pelotas/RS - CEP: 96010-770

Caixa Postal 354

Fone: (53) 32843208

\section{http://wp.ufpel.edu.br/ndh/} e-mail:ndh.ufpel@gmail.com 


\title{
O FICCIONAL E O HORROR: REPRESENTAÇÕES DA TORTURA DURANTE as Ditaduras de SEguranÇa NACiONAL NA AMÉRICA LATINA NA LITERATURA
}

\author{
THE FICCIONAL AND THE HORROR: TORTURE'S REPRESENTANTIONS IN THE \\ PERIOD OF THE LITERATURE'S LATIN AMÉRICA SECURITY NACIONAL
} DICTATURES

\begin{abstract}
Resumo: O presente artigo realiza uma reflexão sobre as relações entre história e literatura, observando de que forma eventos históricos relacionados ao período das Ditaduras civil-militares na América Latina estão representados nas obras literárias selecionadas. A Literatura e a História são expressões narrativas que em grande medida tendem à aproximação; contudo, a História possui uma pretensão de veracidade a qual a Literatura não está necessariamente submetida. A pesquisa dedicou-se a observar como a tortura, empregada constantemente durante os regimes civil-militares em países como Brasil, Uruguai e Chile, foi representada em três obras selecionadas: "O Caderno de Maya", "O irmão alemão" e "Primavera num espelho partido". Foi possível perceber que os autores optaram por apresentar a tortura a partir de personagens masculinos, utilizando muitas vezes subterfúgios para descrever o horror, como o uso de sonhos ou da imaginação de um dos personagens. Foi possível evidenciar que a literatura cumpre um papel importante na discussão deste essencial tema histórico.
\end{abstract}

Palavras-chave: História; Literatura; Tortura; Ditaduras civil-militares.

\section{Literatura e História: a Guerra e a Paz}

A reflexão sobre as relações estabelecidas entre as narrativas literárias e a ciência histórica mostra-se bastante profícua, uma vez que permite observar os limites e as potencialidades de cada área de conhecimento, bem como observar de que modo a literatura pode ser um instrumento de problematização de importantes eventos históricos. A literatura e a história constituem-se em narrativas, as quais muitas vezes aproximam-se de tal modo que podem confundir-se: afinal, quais os propósitos destas formas de observar e representar a realidade? Haveria alguma delimitação aos seus propósitos ou mesmo alguma hierarquia que sobrepusesse estes dois campos narrativos?

De fato, é possível observar que as linhas que separam a Literatura e a

1 Docente da Educação Básica, Técnica e Tecnológica de História do Instituto Federal do Rio Grande do Sul, Campus Bento Gonçalves, Doutora em História pela Universidade Federal do Rio Grande do Sul. Email: leticia.ferreira@bento.ifrs.edu.br 
História são tênues: ambas têm a intenção de contar algo ao leitor e o texto produzido está impregnado por uma série de elementos, tais como o contexto de produção da obra, o público alvo, questões mercadológicas, o posicionamento do autor frente aos eventos narrados, entre outros fatores de influência na redação de uma narrativa. Literatura e História buscam representar uma determinada realidade, a qual é apreendia a partir do filtro estabelecido pelo narrador: não é a realidade em si que é narrada, mas a seleção de alguns aspectos do real que, dentro das condições possíveis em determinado local e em uma temporalidade específica, podem ser abordados. Segundo Chartier,

A relação entre literatura e história pode ser entendida de duas maneiras. A primeira enfatiza o requisito de uma aproximação plenamente histórica dos textos. Para semelhante perspectiva é necessário compreender que nossa relação contemporânea com as obras e os gêneros não pode ser considerada nem como invariante nem como universal. Devemos romper com a atitude espontânea que supõe que todos os textos, todas as obras, todos os gêneros, foram compostos, publicados, lidos e recebidos segundo os critérios que caracterizam nossa própria relação com o escrito. Trata-se,portanto, de identificar histórica e morfologicamente as diferentes modalidades da inscrição e da transmissão dos discursos e, assim, de reconhecera pluralidade das operações e dos atores implicados tanto na produção e publicação de qualquer texto, como nos efeitos produzidos pelas formas materiais dos discursos sobre a construção de seu sentido. (CHARTIER, p.197)

É possível verificar que tanto os textos literários quanto históricos preenchem lacunas, buscando referências para que o narrado possua sentido para o leitor. A escrita da História e de obras ficcionais exige de seus autores interpretação e imaginação, sendo uma das tarefas daquele que narra buscar soluções para a ausência de informações. História e Literatura ocorrem dentro de uma determinada temporalidade, seja o passado ou algum tempo indeterminado pela narrativa. Comumente, apresenta-se a literatura como lócus do encantamento, enquanto a narrativa histórica não possuiria a função (ou capacidade?) de atrair um público mais amplo, estando restrita aos círculos de estudiosos da área. Entretanto, não poderia ser a História um espaço de escrita que não apenas produzisse conhecimento, mas que se valesse de um estilo menos árido, o qual pudesse abranger um público numericamente expressivo?

Talvez seja possível afirmar que não é o modo pelo qual o conhecimento histórico é narrado que diferencie as duas áreas de conhecimento, mas sim os compromissos aos quais ambas estão vinculadas: enquanto o leitor de ficção literária não possui a expectativa de que os feitos narrados na obra condigam com a realidade, exige-se que o historiador 
ultrapasse a verossimilhança e aborde os eventos conforme tais se passaram. Apesar de tal situação não ser possível em sua totalidade, sem dúvida, o historiador busca apresentar seus dados a partir dos vestígios de sua investigação: a produção histórica precisa divulgar as fontes consultadas para a composição do texto e das informações e interpretações nele contidas. Pesavento esclarece que

\begin{abstract}
leitores de História, em princípio, buscam saber como foi, ou mais ainda, a verdade do que foi.Mesmo porque, consagradamente, pesa sobre o historiador o papel de desempenhar a fala autorizada sobre o passado. Mas, mesmo detendo esta autoridade da fala, o historiador se vale dos recursos da linguagem, do esforço retórico do convencimento, das evidências de pesquisa. Estas evidências são a exibição de referências bibliográficas, citações, indicações de fontes e notas de rodapé para mesmo provocar o leitor, como já foi antes assinalado: se não acreditar ou não estiver convencido, refaça meu caminho e comprove por si mesmo... (PESAVENTO, 2003, p. 38)
\end{abstract}

A literatura, enquanto ferramenta para a compreensão histórica de um determinado período, vem sendo recorrentemente utilizada pelos historiadores, desde o início do século XX, com o advento da Escola dos Annales, grupo fundado por estudiosos que propunham uma ampliação dos objetos de estudo da História e, por conseguinte, das fontes que sustentariam tais pesquisas. Deste modo, a literatura apreendida em suas especificidades, poderia ser um instrumento interessante para a compreensão de como os atores de um período específico problematizavam e refletiam sobre um determinado evento histórico. Em relação à trajetória já consolidada dos usos da literatura para os estudos históricos, Grecco expõe que

Tanto a escrita histórica como a literária compartilham um ambicioso projeto de apreender as realidades humanas, evidenciando a força das representações do passado propostas por esses dois diferentes discursos. Nesse sentido, pode-se verificar que a aproximação entre história e literatura já tem um percurso respeitável, de modo que muitos historiadores reconhecem no texto literário a possibilidade de se trabalhar com discursos que, em grau variado, revelam o campo de produção simbólica de uma época. Assim, afirmar hoje que a literatura é fonte histórica já não provoca qualquer polêmica. (GRECCO, 2014, p. 45)

A literatura pode vir a ser fonte histórica se considerar-se que é um espaço de memória, em que se materializam crenças, escolhas, projetos, temores gerados em um contexto histórico, podendo mostrar-se um catalisador para a discussão de eventos históricos. A obra literária, livre das amarras das notas de rodapé, pode, muitas vezes, ultrapassar os fatos contidos nos livros, levá-los a outro tempo e dimensão, baseando-se na metáfora para expressar o que deseja. A literatura, em suas múltiplas demandas, estéticas, 
questionadoras, inovadoras, mostra-se objeto de interesse e presente nos mais diversos ambientes de sociabilidade: bibliotecas públicas ou privadas, escolas, e o estímulo ao acesso às narrativas literárias busca a ampliação de leitores integram projetos educacionais. $\mathrm{O}$ apelo da literatura ficcional e os diferentes temas históricos abordados nas narrativas podem ser o propulsor para o interesse no aprofundamento de conteúdos históricos e a busca por informações em outros modelos narrativos, como as leituras referentes à ciência histórica.

A literatura talvez seja um espaço privilegiado de preservação da memória histórica, bem como pode ser um veículo de denúncia de tópicos os quais o plano da realidade não tem conseguido dar conta. As disputas referentes à interpretação dos fatos históricos, presentes no ambiente acadêmico, também e encontram na literatura e nas seleções realizadas pelos autores das obras literárias sobre o que narrar e o como narrar: em especial, é necessário discutir de que forma temas referentes à história recente são abordadas na literatura. A produção literária pode propiciar um instrumento de combate ao esquecimento e a abordagem de eventos considerados traumáticos em relação à história de um determinado local.

A seleção de eventos históricos, o que é esquecido ou lembrado, parte de uma série de debates e tensões de cunho político-ideológico, e não há eventos que possam ser completamente suprimidos, pois, mesmo quando silenciados no discurso oficial, persiste de forma sub-reptícia, entre aqueles que resistem em esquecer. Pollak explicita que

O longo silêncio sobre o passado, longe de conduzir ao esquecimento, é a resistência que umasociedade civil impotente opõe ao excesso de discursos oficiais. Ao mesmo tempo, ela transmite cuidadosamente as lembranças dissidentes nas redes familiares e de amizades, esperando a hora da verdade e da redistribuição das cartas políticas e ideológicas (POLLAK, 1989, p.5)

A obra ficcional, apesar de não possuir um papel obrigatório a desempenhar em relação à ciência histórica, está inserida em uma determinada coletividade e não pode se eximir de receber influências, ao mesmo tempo em que influencia a constituição de novos olhares e perspectivas sobre diferentes fatos históricos. A literatura pode ser uma ferramenta para romper as muralhas do esquecimento, intencional ou não, abordando as diversas visões sobre eventos considerados traumáticos ou não resolvidos. Gimenes evidencia esta relação literatura/sociedade, explicitando que

trata-se, fundamentalmente, de perceber que esse conjunto de textos, obras, autores, críticas, leitores, polêmicas, estilos, a que chamamos genericamente de "literatura", procura fixar, coletivamente, estados de comportamento, de 
emotividade, de sensações, de raciocínio, de ordenamento da realidade. Ela participa, de forma importantíssima, dos processos históricos e sociais de formação das sensibilidades coletivas, bem como das maneiras como os sujeitos percebem a si mesmos, sua realidade e sua época. (GIMENES, 2014, p.135.)

O esquecimento de determinados eventos históricos pode ser uma prática proposital, mas também pode estar vinculada à própria experiência enquadrar-se como algo tão traumático que se torna penoso narrar os acontecimentos. Haveria situações "inenarráveis", tal a condição de degradação e sofrimentos causados, como seria o caso da tortura, que humilha e despoja de qualquer humanidade não apenas o torturado, exposto e seviciado como coisa, quanto, também, aquele que tortura? É possível representar, ou seja, colocar algo no lugar de um evento, seja palavras ou outros símbolos, que possam explicitar as sequelas de uma experiência traumática? Araújo e Santos evidenciam que

Há aqueles também que trabalham com a memória em situações de extrema agressividade e violência. Nesse caso, observa-se a incapacidade de resposta das vítimas, que, ao não serem capazes de compreender experiências vivenciadas e lhes dar significados, tornam-se incapazes de operar com suas memórias de forma seletiva. A memória, portanto, não pode ser reduzida a instrumento político; ela excede as tentativas de controle (ARAÚJO e SANTOS, 2007, p.101-102.)

A literatura é, sem dúvida, muito mais permissiva e flexível que a história, presa pelas correntes do factual e talvez seja esse um importante aspecto a ser destacado, pois os eventos traumáticos muitas vezes vivenciados em contextos sombrios não recebem uma adequada reparação no plano da realidade, enquanto uma obra ficcional não apenas pode proporcionar um espaço de denúncia, mas também de justiça. Indubitavelmente, as marcas de experiências traumáticas não são facilmente debeladas, e a luta por justiça, reconhecimento e restauração de um equilíbrio ao nível da concretude e do cotidiano não podem ser substituída por nenhuma outra instância. Entretanto, a literatura pode ser um espaço de reflexão sobre as possibilidades frente a uma justiça que não se aplica, para a impunidade, para o abandono das vítimas. A literatura pode, sem dúvida, ser um instrumento fundamental de reparação e de possibilitar a emersão de temas da história recente e que precisam ser debatidos.

A literatura, assim, pode ser um instrumento de colaboração da memória, para permitir que o "não dito" seja expresso de modos diversos, explícita e implicitamente, propiciando um cenário de contestação ao esquecimento, de organização das lembranças. Segundo Pollak, 
existem nas lembranças de uns e de outros zonas de sombra, silêncios, "nãoditos". As fronteiras desses silêncios e "não-ditos" com o esquecimento definitivo e o reprimido inconsciente não são evidentemente estanques e estão em perpétuo deslocamento. Essa tipologia de discursos, de silêncios, e também de alusões e metáforas, é moldada pela angústia de não encontrar uma escuta, de ser punido por aquilo que se diz, ou, ao menos, de se expor a mal-entendidos. (POLLAK, 1989, p.8)

Outro ponto interessante para o debate sobre as potencialidades da literatura diante dos temas vinculados a experiências traumáticas é que a narrativa, geralmente, procura elos de significância que aproximam o leitor da trama, o que poderia permitir a empatia diante das desventuras do personagem, que, fictício pode ser qualquer um e todos ao mesmo tempo. Deste modo, a apreensão da experiência traumática pode atingir públicos diversos e ser expressa em diferentes linguagens. Em relação ao tema específico da tortura, o qual será abordado com maior profundidade em capítulos posteriores, as obras de ficção podem servir como um testemunho sobre os suplícios vivenciados e muitas vezes silenciados. As obras ficcionais podem ter um papel fundamental na medida em que pode trazer para o espaço social uma discussão muitas vezes reprimida. Ginzburg explicita que

\begin{abstract}
A importância da literatura para a consciência social nesse sentido é enorme, por conseguir, através de recursos de construção, certa fidelidade ao impacto da violência funda que resulta aos que viveram, direta ou indiretamente, o impacto da experiência da tortura. (...). O apagamento da memória coletiva das referências à tortura,bem como sua banalização, potencialmente reforçam as chances de naturalizá-la e ignorar a intensidade de seu impacto. O esquecimento é,nesse sentido, em si, uma catástrofe coletiva. (GINZBURG, 2001, p.145)
\end{abstract}

O esquecimento, nunca pleno, é sempre um ato de amordaçar, a si mesmo, ao outro. Deste modo, para compreender as opções feitas por autores de obras literárias em relação às formas de narrar uma experiência que talvez nunca seja passível de ser saneada, é necessário compreender o contexto histórico no qual se insere a prática da tortura enquanto política de estado.

\title{
A tortura e seus usos
}

É impossível precisar em que momento da história a tortura passou a ser empregada; contudo, há referências entre os vestígios e documentos de civilizações da Antiguidade os quais abordam a prática da tortura contra os escravos, considerados objetos, ou como punição para determinados crimes. Eram prescritos castigos que visavam de fato causar dor e sofrimento, variando o grau de intensidade ou o modo de aplicação de acordo com o delito 
cometido; assim, o supliciado poderia sofrer chibatadas, apedrejamento, queimaduras na pele ou mutilação de membros do corpo. A tortura era utilizada enquanto instrumento de penalização e de reparação, sendo muitas vezes o indivíduo condenado a sofrer uma penalidade relativa ao crime cometido, como no caso do roubo, geralmente punido com o decepamento de uma mão. A tortura era explícita e buscava ser exemplar, disseminando o medo e evitando que outros cometessem a mesma infração. A tortura, neste contexto, vincula-se ao âmbito físico, e tem a finalidade de acarretar em sofrimento, considerado como reparador de um dano causado à sociedade.

Posteriormente, a tortura tem como objetivo central a fala, a confissão. Durante o período medieval e a denominada Idade Moderna, a Igreja Católica valeu-se largamente da prática da tortura para perseguir e eliminar indivíduos ou grupos que de alguma forma questionassem ou colocassem em risco os dogmas religiosos. A utilização de um aparato constituído por máquinas específicas para causar sofrimento físico e mutilação demonstra que paulatinamente irá se constituir um corpo teórico referente à tortura: as sevícias passam a ser pensadas, calculadas com mais apuro, e seu intuito ultrapassa a necessidade de castigar, e sim busca a fala, o arrependimento. $\mathrm{O}$ poder temporal também se valia habitualmente da tortura, que será dimensionada com o passar do tempo em uma justiça ascética, livre das paixões e da emotividade. Foucault observa que a tortura tem por finalidade deixar uma marca no supliciado, de tal forma que este seja responsabilizado pelas sevícias sofridas. $\mathrm{O}$ autor aborda a questão do suplício, afirmando que

\begin{abstract}
Em relação à vítima, ele deve ser marcante: destina-se, ou pela cicatriz que deixa no corpo, ou pela ostentação de que se acompanha, a tornar infame aquele que é sua vítima; o suplício, mesmo de tem como função "purgar" o crime, não reconcilia; traça em torno, ou melhor, sobre o próprio corpo do condenado sinais que não devem se apagar; a memória dos homens, em todo o caso guardará a lembrança da exposição, da roda, da tortura ou do sofrimento devidamente constatados. (FOUCAULT, 1987, p.31-32)
\end{abstract}

As marcas da tortura, deste modo, já não precisam estar penas no corpo, para serem vistas pelos olhares dos transeuntes, mas estar no pensamento, na memória e quiçá nos pesadelos do supliciado, sendo constantemente rememoradas pela vítima, que passa a sofrê-las novamente, em um ciclo interminável. Todavia, pouco a pouco, com o advento das correntes filosóficas dos Séculos XVII e XVIII, agrupadas na denominação de Iluminismo, as quais refletiam sobre princípios como liberdade, igualdade e fraternidade, a tortura passou a ser reputada como algo "indecente", que feria sensibilidades e, portanto, não deveria ser realizada (ao menos publicamente...). Assim, com o advento de perspectivas humanistas, cujo ápice pode ser 
vinculado à Declaração Universal dos Direitos Humanos de 1948, a tortura passa a ser condenada e coibida nos mais diversos países.

Porém, a eficácia do combate à tortura requer a compreensão sobre o que é passível de ser considerada tortura, concepção que se adéqua às diferentes temporalidades e espaços. Deste modo, em relação ao conceito de tortura é possível explicitar que

A tortura foi definida pela Associação Médica Mundial em assembleia realizada em Tóquio, a 10 de outubro de 1975 como 'a imposição deliberada, sistemática e desconsiderada de sofrimento físico ou mental por parte de uma ou mais pessoas, atuando por própria conta ou seguindo ordens de qualquer tipo de poder, com o fim de forçar uma outra pessoa a dar informações, confessar, ou por outra razão qualquer (apud Brasil nunca mais, 1985, p.281)

A Declaração Universal dos Direitos Humanos, em seu artigo $5^{\circ}$ e a Constituição Federal brasileira de 1988 , em seu artigo $5^{\circ}$ expressam que "ninguém será submetido à tortura nem a penas ou tratamento cruéis, desumanos ou degradantes" (DECLARAÇÃO UNIVERSAL DOS DIREITOS HUMANOS, 1948). A compreensão da necessidade de estabelecer e universalizar direitos considerados fundamentais e inerentes a qualquer ser humano advém das diversas situações de violação brutal da liberdade, do uso da tortura e da implementação do genocídio de diversos grupos ao longo dos conflitos mundiais e dos processos de descolonização de países da Ásia e da África.

O final da Segunda Guerra Mundial - evento que revelou a capacidade humana para a desumanização, exemplificada pela instauração de um processo fabril de morte que se concretizou no holocausto judeu, entre outros segmentos da sociedade - não significou a abolição da tortura do cotidiano. De fato, a bipolarização político-ideológica que emerge após o conflito mundial, constituindo o período que será denominado Guerra Fria, irá propiciar um campo profícuo para a prática do suplício, uma vez que se cria, então, um novo inimigo, de difícil identificação, pois não usa uma vestimenta específica, nem traços ou uma linguagem que possa caracterizá-lo. Neste momento, é possível perceber a criação de um inimigo interno, não mais oriundo de um determinado local e sim imbuído de uma perspectiva, a qual se contraporia aos "interesses nacionais". De fato, tais interesses eram ditados por um grupo minoritário, e comumente estava associado às demandas do capital internacional aliado às elites locais, os quais desejavam combater o avanço de projetos reformistas ou alternativos ao modelo até então hegemônico. Esta visão consolida-se no que será conhecida como Doutrina de Segurança Nacional (DSN), a qual, baseada em uma perspectiva que não tolera 
a dissensão, passa a promover a perseguição de todos que não se adéquam ao discurso hegemônico imposto pelo Estado. Padrós explicita que

\begin{abstract}
Segundo os princípios da DSN, o cidadão não se realiza em função do seu pertencimento a uma determinada classe social, mas era a identidade e a consciência de pertencimento a uma comunidade nacional coesa o que o potencializava e viabilizava a satisfação das suas demandas. Neste sentido, a existência de antagonismos sociais ou questionamentos que explicitassem interesses de classe por detrás dos setores políticos dirigentes era percebida como nociva aos interesses da "nação", sendo combatida como tal (PADRÓS, 2004, p.45-46).
\end{abstract}

Assim, o estabelecimento da Doutrina de Segurança Nacional e a necessidade de identificar - e eliminar - o inimigo interno, oculto pela invisibilidade do cotidiano, colocará a prática da tortura novamente em pauta, agora como uma ferramenta de combate. Tal perspectiva está alinhada às experiências vinculadas à descolonização dos países anteriormente dominados pelos europeus, como por exemplo, a Indochina e a Argélia, ambos subjugados pela França por um longo período. A luta empreendida contra o Nazismo alemão e o Fascismo italiano, sustentada pelo discurso pródemocracia e liberdade, gerava um importante paradoxo: enquanto lutavam contra o invasor alemão, ingleses e franceses, por exemplo, constituíam-se como invasores nos continentes africano e asiático. Carentes de recursos bélicos que pudessem ser equiparados ao aparato militar europeu, grupos que visavam a expulsão dos dominadores estrangeiros valiam-se de estratégias de guerrilha e atos considerados de terrorismo. A libertação da Indochina foi, em grande medida, bem sucedida devido ao desgaste provocado pelo uso frequente de táticas que surpreendiam o inimigo, o qual tinha dificuldade em identificar ou prever a próxima ação dos opositores. A Doutrina de Segurança Nacional embasou-se na experiência francesa, especialmente no processo de combate estabelecido na Argélia, sendo o principal marco a famigerada Batalha de Argel, No intuito de evitar uma nova derrota militar tal qual ocorrera na Indochina, a França, país reconhecido como berço dos princípios humanitários e defensor das liberdades, lançou mão recorrentemente da tortura não apenas para a eliminação do inimigo, mas como instrumento de obtenção de informações. Segundo Duarte-Plon:

A tortura não, evidentemente, inventada pelos militares franceses na Argélia, nem mesmo na Indochina. Já fora usada em larga escala pela Geheime Staatspolizei [Polícia Secreta do Estado - Gestapo], pelo regime stalinista, pelo Império Romano e pela própria Igreja durante a Inquisição. Mas na Argélia, pela primeira vez foi aceita como um método de guerra, recomendada pelos chefes militares e aprovada pelos responsáveis políticos. (DUARTE-PLON, 2016, p.41-42.) 
Assim sendo, é possível referir que neste contexto de constituição e aprofundamento de um quadro de histeria política, os setores armados dos países da América Latina, especialmente o Exército, vão sendo treinados a partir deste viés, em espaços constituídos para tal, como a Escola das Américas, onde militares estadunidenses e também franceses - considerados experts neste tipo de guerra, dado seu know how - realizavam treinamentos no que denominavam de "guerra contrarrevolucionária", enquanto competiam pela venda de armamentos mais efetivos e modernos aos países da América Latina. Desta forma, sem desmerecer o importante aspecto ideológico envolvido, as questões econômicas também se relacionam ao estabelecimento deste novo inimigo e do reforço ao constante estado de alerta entre os integrantes das Forças Armadas dos países da América Latina.

A tortura, diante deste contexto de medo generalizado, porém muitas vezes velado, constitui-se pouco a pouco como um método considerado eficaz para o combate ao inimigo interno, sendo os suplícios, variados, estudados detalhadamente e aplicado com tons de cientificidade considerados essenciais para implantar o Terror de Estado, ou seja, um Estado que utiliza seu aparato repressivo para oprimir a própria população. Na América Latina, o exemplo cubano, cujo processo revolucionário concretiza-se em 1959, acarreta uma intensificação da vigilância e do temor de que uma experiência semelhante fosse adotada por outro país. A instauração de Ditaduras de Segurança Nacional nos países latino-americanos passa a implementar políticas de difusão de medo, associadas, entre outros fatores, à prática da tortura. Padrós analisa esse contexto, evidenciando que

\begin{abstract}
Os mecanismos implementados pela violência estatal visaram as organizações e os indivíduos que podiam representar perigo de resistência ao projeto em andamento; impuseram também a médio prazo, formas anestésicas de convivência, fosse através da "cultura de terror" da autocensura ou até da possibilidade de cooptação. A estabilidade e a apatia resultante do medo da volta do recurso sistemático à força condicionou um clima político que se ajustou adequadamente aos anseios e necessidades da alta burguesia e do capital internacional. (PADRÓS, 2012, p.48)
\end{abstract}

A tortura é, sem dúvida, um instrumento essencial em relação à disseminação do terror social, além de uma arma para obtenção de informações. Indubitavelmente, a constituição de um sistema de informações efetivo foi essencial para a vitória militar sobre os grupos de resistência às ditaduras civil-militares implantadas entre as décadas de 1960 e 1980 em diversos países latino-americanos. Contudo, sua utilização, em especial no Brasil, tinha outros propósitos, como abalar psicologicamente o supliciado. Duarte-Plon, ao abordar os relatórios da Anistia Internacional sobre o governo 
brasileiro, explicita que

(...) podemos afirmar que a tortura no Brasil tem uma característica diferente daquela praticada na Idade Média, pela Gestapo na França ou pelo Exército francês na Argélia. No Brasil, a tortura não serve apenas para obter confissões ou informações. Por isso se torturam familiares de suspeitos, mulheres são torturadas diante de seus maridos, presos são supliciados diante de outros presos: para que as testemunhas possam contar os horrores a que assistiram e ajudem a criar um clima de terror, medo e insegurança propício à submissão. (DUARTE-PLON, 2016, p.75.)

É possível observar que a tortura implementada neste período segue uma série de referências técnicas, aplicando métodos científicos que buscam medir a dor e implementá-la de modo a que o seviciado não morresse durante a sessão de torturas, o que nem sempre era concretizado. Em outras situações, a tortura andava atrelada à eliminação do supliciado, cujo corpo era eliminado, e o indivíduo passava a integrar uma extensa lista de desaparecidos. O desparecimento do inimigo político foi uma importante ferramenta de disseminação da tortura psicológica, pois além do pânico provocado por esta estratégia, o medo era difundido entre os familiares da vítima, que eram muitas vezes acusados de mentir sobre o destino do indivíduo. A prática da tortura, assimilada entre os representantes dos regimes civil-militares como válida e efetiva, está, sem dúvida relacionada à tradição autoritária da sociedade brasileira, a qual se constitui a partir do genocídio indígena e da violência da escravidão. A tortura, em diversos momentos é banalizada por aquele que suplicia, o qual possui uma série de dispositivos de promoção da dor ao seu dispor. Segundo documentos da anistia internacional de 1972 e apresentados por Duarte-Plon,

havia uma ampla gama de suplícios à disposição do torturador: choque elétricos nos olhos, na boca, nas partes genitais (vagina, pênis e ânus), introdução de um bastão no ânus, afogamento; injeção do "soro da verdade"; telefone (tapa nas orelhas); pau de arara (nu, suspenso, a cabeça pendendo para baixo, braços e calcanhares atados em uma barra de ferro, o preso é espancado e submetido a choques elétricos por horas); o preso é despertado de hora em hora durante a noite; o preso era levado para um local isolado, com um capuz preto na cabeça, para simulação de fuzilamento; mulheres eram espancadas e chicoteadas em todo o corpo, inclusive nas partes genitais (...). (DUARTE-PLON, 2016, p. 74)

A tortura, no entanto, é sempre um ato de covardia, que macula não apenas do seviciado, mas também o torturador. Deste modo, são construídos discursos, aos quais aquele que aplica os suplícios remete-se para justificar o injustificável. Nas raras situações em que torturadores admitiram a implementação dos sofrimentos em inimigos políticos, buscava-se ressignificar 
a tortura como um verdadeiro ato "heroico", uma vez que as informações obtidas por esse meio salvariam a vida de dezenas de pessoas. $\mathrm{O}$ discurso que busca viabilizar o crime da tortura traz em si uma série de paradoxos, entre os quais a perspectiva de desumanizar o torturado, inferiorizando o inimigo, tratando-o não como um combatente, mas como um "subversivo", o que ao mesmo tempo em que o descaracteriza em sua legitimidade militante, por conseguinte desvaloriza a ação do torturador enquanto um suposto herói. $\mathrm{O}$ torturador apresenta sua ação como necessária, como imprescindível para as novas estratégias de luta impostas pela realidade do combate ideológico, e a repetição e o apego a tais argumentos tornam-se crenças, dogmas. O crime perpetrado pela tortura deve, posteriormente, ser anistiado, esquecido, dado como inevitável e, portanto, perdoável. O que se olvida nesta concepção é que a tortura nunca passa, nunca termina, e as profundas cicatrizes deixadas por sua prática, visíveis ou não, não podem ser sanadas. A adoção da tortura significa um caminho sem retorno, sendo talvez o ato mais vil que a mente humana pode vir a engendrar. É a abertura da caixa de Pandora, e ao enxergarse monstro, o ser humano esquece a face que um dia teve, e segue desumanizado e sem arrependimentos.

A partir das reflexões até o momento abordadas relativas à tortura, é possível questionar de que modo a literatura aborda este tema considerado comumente espinhoso, ou até polêmico. A tortura pode ser abordada em seu horror, buscando o choque, a empatia? Ou o mais recorrente seria que o sofrimento imposto fosse narrado de forma metafórica, dado o fato de que esta experiência ser de alguma forma inenarrável? No intuito de abordar essa temática, foram selecionadas três obras literárias latino-americanas, uma chilena, uma uruguaia e uma brasileira, as quais tratavam sobre o tema das Ditaduras de Segurança Nacional na América Latina. A partir desta escolha, procurou-se identificar inicialmente os autores das obras e sua relação com os temas apresentados nas obras, os personagens que sofrem a tortura e de que modo esta situação extrema é apresentada.

\section{A narrativa e a dor}

O presente estudo procurou observar obras de autores de nacionalidades diversas buscando apreender se havia semelhanças em relação às formas de narrar a tortura, considerando que a experiência da implementação das Ditaduras civil-militares de Segurança Nacional foi diferente em cada país, uma vez que se vinculava também a características próprias de cada nação. Neste primeiro momento as obras selecionadas foram 
"O caderno de Maya" da chilena Isabel Allende, "Primavera num espelho partido" do uruguaio Mário Benedetti e "O irmão alemão" do brasileiro Francisco Buarque de Holanda. A análise da biografia de cada autor permite evidenciar que todos foram atingidos diretamente pelos regimes civil-militares implantados em seus países: Salvador Allende, presidente que sofre o violento golpe chileno e acaba por cometer suicídio era tio de Isabel, que após a implantação da ditadura, busca refúgio primeiramente na Venezuela e depois nos Estados Unidos; o exílio também é o destino de Chico Buarque, importante e premiado compositor brasileiro, filho de um dos principais intelectuais da área de humanidades no Brasil, Sérgio Buarque de Holanda, bem como de Mário Benedetti, o qual possui uma importante atuação no cenário político uruguaio. Deste modo, a ficção pode estar vinculada a uma necessidade de memória, de denúncia, de catarse do sofrimento indizível, mas que, veiculado de modo poético, pode se mostrar libertador. Para tanto, seria necessário observar testemunhos orais, entrevistas, observar de forma mais detalhada a biografia de cada escritor, o que não é o enfoque da presente investigação. Todavia, é fundamental posicionar os autores frente ao que se narra, para compreender as opções feitas nas diversas situações.

A obra "O Caderno de Maya", de 2009, narra a história de uma jovem que se envolve com um grupo de criminosos e, no intuito de protegê-la, sua avó a envia para uma distante ilha no Chile, local no qual ela deve redescobrirse, assim como a sua própria história. A narrativa centra-se nas desventuras de Maya, que após a morte do avô pelo qual foi criada e com o qual possuía um importante vínculo afetivo, passa a cometer uma série de atos infracionais, sofrendo de depressão e, em terras chilenas, acaba por descobrir mais sobre o passado da avó e de seu próprio país. Na ilha, é acolhida por Manuel Arias, misterioso amigo de sua avó, e a sensação de segredo que perpassa a história está, em grande medida, associada ao tema da ditadura civil- militar chilena. Ao final da obra, há a revelação de que o silencioso e sisudo Manuel Arias foi vítima de torturas, preso político que presenciou a morte de seu amigo Felipe Vidal, primeiro marido de Nini, avó de Maya. Deste modo, a autora procura abordar os primeiros momentos do processo ditatorial, instaurado pelo golpe de 11 de setembro de 1973 e que buscou rapidamente a eliminação da oposição. Em relação à implantação da ditadura chilena, Guazzelli explicita que

Os primeiros meses da ditadura foram dedicados à implementação do terror de Estado, com o aplastamento da resistência nos cordones industriais, prisões, torturas e execuções sumárias de representantes sindicais, lideranças políticas da Unidade Popular, intelectuais envolvidos com o programa de transformações sociais, estudantes, operários, estrangeiros que haviam emigrado de países latino-americanos já sob a tutela de governos militares (GUAZZELLI, 2004, 
p.98).

O personagem Felipe Vidal é exatamente um destes intelectuais associados ao presidente Salvador Allende, o qual trabalhava em um canal de televisão do governo e por isso teria sido preso neste primeiro momento. Apesar de ter passado um período escondido, Felipe, para o desespero de sua esposa, resolve se entregar, uma vez que diversos de seus companheiros de trabalho e de luta haviam sido capturados e ele se sentia envergonhado e constrangido de estar se escondendo. O personagem, apesar de ser apresentado de modo bastante superficial, parece não dimensionar a excepcionalidade do ocorrido, como se ele fosse estar protegido por um aparato jurídico de proteção que de fato só pode existir em períodos democráticos. Manuel Arias acompanha o desenrolar dos acontecimentos que vitimam Felipe, o que pode ser observado na seguinte passagem

Manuel Arias estava na Villa Grimaldi, inaugurada fazia pouco como quartel da
DINA, numa das celas de tortura, de pé, esmagado contra outros prisioneiros
imóveis. Entre eles se encontrava Felipe Vidal. A quem todos conheciam por
seu programa de televisão. (...) Depois de dois dias, levaram Felipe Vidal para
ser interrogado. Não voltou. Os presos costumavam se comunicar com
pancadinhas e arranhões nos tabiques de madeira que os separavam. Assim,
Manuel ficou sabendo que Vidal tinha sofrido uma parada cardíaca enquanto
levava choques. Seu corpo, como o de tantos outros, foi lançado ao mar”.
(ALLENDE, 2011, p.389-390.)

Nesta obra, Isabel Allende aborda apenas de forma breve a situação da tortura, sendo a morte de Vidal revelada apenas nos últimos capítulos. Contudo, é um tópico importante, dado que é criada uma certa expectativa ao longo da narrativa, no qual a autora mostra não apenas a tortura, mas suas fatais consequências, incluindo o desaparecimento do corpo do personagem, prática comum nas Ditaduras de Segurança Nacional. Assim, ao final da leitura da obra, esta informação persiste junto ao leitor, pois é uma informação essencial para a compreensão da história de Maya e sua resolução.

Mário Benedetti, na obra Primavera num espelho partido, aborda a ditadura instalada no Uruguai a partir de uma série de olhares: Santiago, o protagonista, está preso e exilado em seu próprio eu, distante de seus entes queridos, com os quais tem um contato muito efêmero, já que suas cartas são vigiadas; sua esposa Graciela, vencida pela frouxidão dos laços com o marido, imposta pelo tempo e pela falta de comunicação, acaba por se apaixonar por outro; a filha Beatriz, em sua curiosidade infantil, procura entender os eventos que a envolvem; Dom Rafael, pai de Santiago, procura recuperar sua vida, rememorando diferentes acontecimentos de sua vida. Há também os capítulos que se referem ao exílio vivenciado pelo autor, mesclando a narrativa ficcional 
a fatos autobiográficos. A tortura na referida obra literária é retratada de modo poético, quase uma fantasia do protagonista, que aborda a situação de um amigo e uma das consequências da aplicação da tortura - a loucura:

conseguiram arrastar o Andrés até a loucura/ talvez isso tenha lhe acontecido por excesso de inocência excesso de fé no homem/ tudo o surpreendia sempre pensava até aqui chegaram e acabou não podem ser tão cruéis mas sim eles eram / vou convencê-los e começava a falar e arrebentavam sua boca/ excesso de inocência por isso enlouqueceu". (BENEDETTI,2009, p. 196.)

Chico Buarque, em $\mathrm{O}$ irmão alemão, narra em primeira pessoa a história de Ciccio, filho de Sérgio de Holander e Assunta, o qual descobre que seu pai teve um filho fora do casamento durante sua estadia na Alemanha. A obsessão em descobrir o paradeiro do irmão alemão e em resolver situações vinculadas ao cotidiano bem como as tensões na relação de Ciccio com os demais membros da família têm como pano de fundo a implementação da ditadura civil-militar e toda a sua truculência, nas figuras de Ariosto, um personagem próximo a Ciccio e seu próprio irmão Mimmo, galanteador e bon vivant, que acaba por desaparecer após se envolver com uma argentina relacionada com a resistência ao governo de seu país. Chico Buarque aborda a questão da tortura em toda a sua crueza, porém atenuada pelo fato de que os suplícios são imaginados por Ciccio. Em um primeiro momento, as sevícias são sofridas por Ariosto, o qual é procurado por sua mãe, a famosa estilista Eleonora Fortunato:

Ou vai ver que, para Eleonora Fortunato, a esta altura o Ariosto já estará tão provado em espancamentos, choques elétricos e vexames, que o flagelo de ser corno seria quase um refrigério. De fato, em pesadelo recente, lembro-me de tê-lo visto com os pulsos presos a uma corda, e ser assim alçado em pêndulo até desfalecer, com os ombros desarticulados. $\mathrm{E}$ ao me perder em fuga pelos corredores desse pesadelo, encontrei-o no chão de um calabouço, de mãos e pés atados, o torso em convulsões, como se as vísceras lhe fossem roídas, talvez por um rato atochado cu adentro. (HOLANDA, 2014, p.143)

Ciccio também se imagina sofrendo a violência que atinge amigos, conhecidos, seu irmão, demonstrando o caráter de insegurança e o fato de que qualquer um poderia ser alcançado pelo longo braço da repressão. $\mathrm{O}$ personagem aborda a tortura indiscriminada, que recai também sobre aqueles que nada poderiam confessar por nada saberem. A tortura que não perdoa, a tortura que é imperdoável:

Mas eu não estaria mais lá, o inspetor Borges teria me arrastado para uma conversinha no quartel-general do Exército. Amarrado num assento metálico, cheio de fios espetados pelo corpo nu, era esperável que eu tivesse muito o que contar do meu melhor amigo, um cabra com colhões no dizer dos seus algozes, 


\begin{abstract}
um que suportou sem abrir o bico o que ninguém suporta, um que terminou seus dias feito um zumbi de tanta porrada no crânio e tanto pentotal nas veias. Já eu, submetido a descargas elétricas intermitentes, em dúvida se era mais lancinante a dor em si ou sua expectativa, não pretenderia me tornar um herói da resistência. Mas tampouco teria como cooperar no interrogatório sem nada saber dos descaminhos do meu amigo, dos seus colegas de armas, dos seus pontos de encontro, do organograma de seu grupo, de seus nomes de guerra. Só me viriam à cabeça segredos de minha infância com o Pernalonga, o Capitão Marvel, o Homem Borracha e que tais, e ao ouvir os meus balbucios, o major enfurecido aceleraria a manivela de modo a intensificar a corrente elétrica, o que me provocaria vômitos, convulsões e inopinadamente, uma parada cardíaca. (HOLANDA, 2014, p.187-188)
\end{abstract}

Deste modo, é possível verificar que os diferentes autores analisados, em certa medida engajados pessoalmente na denúncia e na memória dos crimes contra a humanidade vinculados à tortura, busca diferentes subterfúgios para abordar o tema: a tortura e a morte dela decorrente podem estar vinculadas a um segredo a ser revelado ou algo tão atroz que só pode dizer respeito ao imaginário, a um pesadelo. Contudo, ela está ali presente, suas consequências são sentidas em todo o conjunto de personagens que esperam, que temem, que procuram seus entes queridos desaparecidos pela violência. Assim sendo, a literatura não pode sanar as mazelas acarretadas pelo emprego da tortura como prática de combate ao inimigo político, mas sem dúvida pode ser uma importante ferramenta de problematização e reflexão sobre um tema ao mesmo tempo inenarrável em toda a sua dimensão desumanizadora, mas sobre o qual não é possível calar-se.

\title{
Considerações Finais
}

A tortura empregada como arma de combate durante as Ditaduras de Segurança Nacional da América Latina nas décadas de 1960 a 1980 deixaram marcas irreparáveis em todos os envolvidos, sejam aqueles que aplicaram a tortura ou aqueles que foram supliciados. A tortura desumaniza e a impunidade sobre esses crimes vinculada até mesmo a promoção do esquecimento destes eventos, intensifica a não reparação do mal sofrido. A literatura mostra-se um importante veículo para problematizar esse tema sendo um espaço adequado para a denúncia e a criação de empatia.

História e Literatura podem estar associadas para melhor compreendermos como uma sociedade aborda seus traumas. As obras selecionadas demonstram que as questões vinculadas à tortura estão presentes no ficcional e podem ser importantes para sensibilizar e, principalmente, não deixar que este trágico período da América Latina seja esquecido. 


\section{Referências}

ALLENDE, Isabel. O Caderno de Maya. Rio de Janeiro: Bertrand Brasil, 2011.

ARAÚJO, Maria Paula Nascimento; SANTOS, Myriam Sepúlveda dos. História, memória e esquecimento: implicações políticas. Revista Crítica de Ciências Sociais, Coimbra, no 79, p. 95-111, dez. 2007.

ARQUIDIOCESE DE SÃO PAULO. Brasil, nunca mais. Petrópolis: Vozes, 1985.

BENEDETTI, Mário. Primavera num espelho partido. Rio de Janeiro: Objetiva, 2009.

DALCASTAGNÉ, Regina. Da senzala ao cortiço - história e literatura em Aluísio Azevedo e João Ubaldo Ribeiro. Revista Brasileira de História, São Paulo, v. 21, nº 42, p. 483-494, 2001.

DUARTE-PLON, Leneide. A Tortura como arma de guerra - da Argélia ao Brasil: como os militares franceses exportaram os esquadrões da morte e o terrorismo de Estado. Rio de Janeiro: Civilização Brasileira, 2016.

FICO, Carlos. História do tempo presente, eventos traumáticos e documentos sensíveis: o caso brasileiro. Varia História, Belo Horizonte, vol. 28, $\mathrm{n}^{\circ}$ 47, p. 43-59, jan/jun 2012.

FOUCAULT, Michel. Vigiar e Punir: o nascimento da prisão. Petrópolis: Vozes, 1987.

GIMENES, Renato Aloizio de Oliveira. Oswald de Andrade: literatura como política. In: RAGO [et.al.]. Narrar o Passado, repensar a história. Campinas: UNICAMP/IFCH, 2014, p.133-172.

GINZBURG, Jaime. Escritas da Tortura. Diálogos Latinoamericanos, Dinamarca, núm. 3, pp. 131-146, 2001. Disponível em $<$ http://www.redalyc.org/articulo.oa?id=16200306> Acesso em: 20 mai. 2017.

GRECCO, Gabriela de Lima. História e Literatura: entre narrativas históricas e literárias, uma análise através do conceito de representação. Revista Brasileira de História e Ciências Sociais, v. 6, n. 11, p. 39-53, 2014. 
GUAZZELLI, César Augusto Barcellos. A revolução chilena e a ditadura militar. In: WASSERMAN, Cláudia; GUAZZELLI, César Augusto Barcellos; MIX, Miguel Rojas (et.al.). In: Ditaduras Militares na América Latina. Porto Alegre: Editora da UFRGS, 2004, p.79-102.

HOLANDA, Chico Buarque de. O Irmão Alemão. Rio de Janeiro: Companhia das Letras, 2014.

OLIVEIRA, Luciano. Ditadura militar, tortura e história: a vitória simbólica dos vencidos. Revista Brasileira de Ciências Sociais, vol. 26, núm. 75, p.0725, fevereiro de 2011.

PADRÓS, Enrique Serra. A ditadura cívico-militar no Uruguai (1973-1984): terror de Estado e segurança nacional. In: WASSERMAN, Cláudia; GUAZZELLI, Cesar Augusto Barcellos. Ditaduras Militares na América Latina. Porto Alegre: Editora da UFRGS, 2004, p.45-78.

PADRÓS, Enrique Serra. América Latina: ditaduras, segurança nacional e terror de Estado. Revista História e luta de classes, v. 4, p.43-49, 2012.

PESAVENTO, Sandra Jatahy. O mundo como texto: leituras da História e da Literatura. History of Education Journal, v. 7, n. 14, p. 31-45, 2003.

POLLAK, Michel. Memória, esquecimento, silêncio. Revista Estudos Históricos, Rio de Janeiro, vol. 2, n. 3, p.3-15, 1989.

\footnotetext{
Abstract: The purpose of this article is to analyze how historical events related to the period of civil-military dictatorships in Latin America are represented in the selected literary works. Literature and History are narrative expressions that tend to approximation to a large extent; however, History has a claim to truthfulness to which Literature is not necessarily subjected. The present research study aimed to observe how torture, constantly used during civil-military regimes in countries such as Brazil, Uruguay and Chile, was represented in three selected works: "O Caderno de Maya", "O irmão alemão", and "Primavera num espelho partido". It was possible to realize that the authors chose to present torture based on male characters, often using excuses to describe horror, such as dreams or the imagination of one of the characters. Thus, it was possible to highlight that Literature plays an important role in the discussion of this essential historical theme.
}

Keywords: History; Literature; Torture; Dictature civil-military 